\title{
Experiencing human energy as a catalyst for developing leadership capacity
}

Book or Report Section

Accepted Version

Vogel, B. (2017) Experiencing human energy as a catalyst for developing leadership capacity. In: Koonce, R., Robinson, P. and Vogel, B. (eds.) Developing Leaders for Positive Organizing. Emerald, pp. 275-306. ISBN 9781787142411 doi: https://doi.org/10.1108/978-1-78714-240-420171022 Available at https://centaur.reading.ac.uk/82079/

It is advisable to refer to the publisher's version if you intend to cite from the work. See Guidance on citing.

To link to this article DOI: http://dx.doi.org/10.1108/978-1-78714-240-420171022

Publisher: Emerald

All outputs in CentAUR are protected by Intellectual Property Rights law, including copyright law. Copyright and IPR is retained by the creators or other copyright holders. Terms and conditions for use of this material are defined in the End User Agreement.

\section{www.reading.ac.uk/centaur}

\section{CentAUR}

Central Archive at the University of Reading 
Reading's research outputs online 
Experiencing Human Energy as a Catalyst for Developing Leadership Capacity

Bernd Vogel

Henley Business School, University of Reading

Emerald Group Publishing (in press) 


\section{Experiencing Human Energy as a Catalyst for Developing Leadership Capacity ${ }^{1}$}

Today's often-cited ambiguous, complex, or uncertain contexts in which organizations operate ask increasingly for collective and interdependent interactions from organizational members. Consequently, leadership can be depicted as a relational, co-created, and collective phenomenon that involves various organizational members (Bradbury \& Lichtenstein, 2000; Denis, Langley, \& Sergi, 2012; DeRue \& Ashford, 2010; Koonce, 2016). This requires an expanded scope of leadership development that includes building the capacity of individuals as much as collectives who engage in leadership (Day \& Dragoni, 2015; Day \& Harrison, 2007). To respond to this need, this chapter explores how the collective experiences of human energy in an organization can generate leadership capability at multiple levels and support future flourishing and organizational performance. The chapter builds on a strengths-based view of individuals and organizations and integrates human strengths and their generative dynamics in organizations (Cameron, Dutton, \& Quinn, 2003; Quinn, Spreitzer, \& Lam, 2012) with leadership development (DeRue \& Workman, 2011). Specifically, I explore how human excellence may unlock and generate leadership capabilities in organizations to support positive human and organizational functioning.

In particular, I focus on collective and individual human energy (e.g., Cole, Bruch, \& Vogel, 2012; Quinn \& Dutton, 2005; Quinn et al., 2012; Shippers \& Hogenes, 2011; Vogel \& Bruch, 2011) and their impact on building leadership capability because both tend to bring about positive deviance in organizations (Spreitzer \& Sonenshein, 2004). As such, this chapter helps to identify the nature of positive development experiences that impact leadership capability and the underlying mechanisms of how positive experiences may

\footnotetext{
${ }^{1}$ Acknowledgements: I would like to thank Ana Margarida Graça, Henley Business School, University of Reading, and Amal Ahmadi, Henley Business School, University of Reading, for their invaluable suggestions and support for the chapter.
} 
facilitate leadership development (DeRue \& Workman, 2011). Research typically investigates what leadership can do to create performing, energetic, and flourishing organizations (e.g., Bruch \& Vogel, 2011; Quinn, 2015; Raes, Bruch, \& De Jong, 2013). However, this chapter turn this sequence of events around and explore a different question: When individuals and collectives who are at their best and thriving feel energized, how can this energy initiate leadership capacity in managers, collectives, and individual employees? Building on the generative and dynamic functioning of human energy (Quinn et al., 2012), and considering a multi-level perspective to address the complexity of organizations, I unpack its dynamics for on-the-job leadership development.

Research on leadership development suggests that leadership learning not only takes place through programs or interventions, but also experiences on the job that can shape leadership capacity (McCall, 2010; Tannenbaum, 1997). Research often focuses on learning from adverse situations and hardship, as well as processes or episodes at work that encompass positive valence experiences (DeRue \& Workman, 2011), such as collective human energy or individual human energy, which have the potential to support the creation of collective- and individual-level leadership. For instance, a manager's perception of strengths in subordinates attributes can stimulate the manager's empowerment perception and instill heightened levels of leadership (Howell \& Shamir, 2005). However, overall this lens of research is scarce.

Building on existing research in human energy, leadership, leadership development, and identity, this chapter explores the following three perspectives: First, how can episodes of individual and collective human energy function as positive developmental experiences for creating leadership capability that expands an individual's or a collective's current leadership knowledge, skills, abilities, motivations, self-concept, and identity? In exploring this question, I highlight factors and mechanisms that might help to explain and initiate the generative relationship between developmental experiences of positive energy at work and 
the creation of individual and collective leadership learning and development. Second, I expand multi-level research in human energy and leadership development by exploring how individual human energy and collective human energy relate to developing facets of leadership capacity at different analytical levels - team, managers, or employees. Third, the chapter explores individual attributes, facets of teams, and organizational-level positive work environments that are supportive of the human energy-developing leadership capacity relationships.

\section{Human Energy, Leadership, and Leadership Development}

\section{Collective and Individual Human Energy}

Research in the last century introduced human energy as a resource for an organization to perform its activities (Katz \& Kahn, 1966). Different intensities of energy were also introduced, with a distinction being made between non-activated (latent) and activated (in motion) forms of energy (Etzioni, 1968). Research on human energy was reinvigorated by work on biological and psychological theories of human functioning (Ryan \& Frederick, 1997) and an increasing emphasis on promoting positive, rather than merely negative organizational phenomena, as reflected in areas of positive psychology and positive organizational scholarship (e.g., Cameron, et al., 2003) and research on energy (Cole, et al., 2012; Quinn \& Dutton, 2005; Vogel \& Bruch, 2011).

Research on human energy has made significant advances over the last two decades and transitioned from a state where energy was "a construct that organizational scholars use but seldom define" (Quinn \& Dutton, 2005, p. 36) to a phenomenon that has become a key element for scholars who focus on strengths and positive, reinforcing processes and dynamics in organizations (Cameron, et al., 2003; Quinn, et al., 2012). Overviews have begun to emerge in the scholarly literature in which energy's scope and its mechanisms are explored 
(Quinn et al., 2012; Shippers \& Hogenes, 2011; Vogel \& Bruch, 2011). Energy research shows that it is related to various organizationally relevant outcomes and is a factor that may explain individual and collective functioning in organizations (Cameron, et al., 2003, 2004; Cole et al., 2012).

Energy research also addresses a multi-level space (from individual to collective human energy); the multi-dimensional nature of energy (affective, cognitive, and behavioral); as well as its different valences, e.g., positive and negative energy (Vogel \& Bruch, 2011). This chapter conceptualizes human energy by initially distinguishing collective and individual human energy in organizations to investigate how episodes of high-energy experiences can affect the development of leadership capacity.

Collective human energy. Collective human energy is the force or a resource (Katz \& $\&$ Kahn, 1966) of a collective unit - organization, department, team or initiative - in pursuit of its goals (Bruch \& Vogel, 2011; Dutton, 2003) and manifests as a multi-faceted phenomenon (Cross, Baker, \& Parker, 2003; Vogel \& Bruch, 2011). Organizational energy is thought to manifest in four different collective energy states: productive energy, comfortable energy, resigned inertia, and corrosive energy (Bruch \& Vogel, 2011), based on two dimensions: intensity (high-low or, respectively, activated and non-activated forms of energy, Etzioni, 1968), which refers to the strength or level of organizational energy experienced in a collective unit when it is active or alert; and the quality of organizational energy (positive-negative) that characterizes the extent to which a unit's energy is constructive or destructive of the company goals.

This chapter investigates the impact of positive episodes on creating leadership capacity and thus I specifically focus on positive energy or productive organizational energy, which refers to "the shared experience and demonstration of positive affect, cognitive arousal, and agentic behavior among unit members in their joint pursuit of organizationally salient objectives" (Cole et al., 2012, p. 447). Affective energy is the shared experience of positive 
emotional arousal due to their enthusiastic evaluation of work-related issues (cf. Cole et al., 2012; Quinn \& Dutton, 2005). Cognitive energy reflects the joint experience of cognitive activation, and behavioral energy refers to members' joint efforts designed to benefit the organization (Cole et al., 2012).

Productive organizational energy manifests as a higher-level, organizational phenomenon (Kozlowski \& Klein, 2000; Morgeson \& Hofmann, 1999) conceptualized as a collective temporary emergent state (Marks, Mathieu, \& Zaccaro, 2001). It emerges via mechanisms that build on the interactive nature of work in organizations such as interindividual interactions in settings of mutual dependence (Cole et al., 2012) or double interacts (Morgeson \& Hofmann, 1999). Organizational members also develop shared interpretation, when they are exposed to the same events (Kozlowski \& Klein, 2000), or experience affective and cognitive contagion processes (Barsade, 2002).

Experiencing energy at the unit level or individual level has been related to various beneficial outcomes for individuals and organizations, such as enhanced well-being (Dutton, 2003), creative work involvement (Atwater \& Carmeli, 2009), job engagement and job performance (Owens, Baker, McDaniel Sumpter, \& Cameron, 2016), improved coordination (Quinn \& Dutton, 2005), or collective goal commitment and job satisfaction (Cole et al., 2012). Subsequently, authors have explored the role of leadership in facilitating or eliciting human energy in organizations (Bruch \& Vogel, 2011; Cameron 2008; Raes, Bruch, \& De Jong, 2013). This chapter explores how episodes can manifest as positive challenges, strengths, or positive valence experiences when units or teams are part of the work assignments in which positive collective energy, i.e., heightened levels of affect, cognitive activation, and behavior for shared goals (DeRue \& Workman, 2011), individually and collectively stimulate managers' and employees' leadership capability.

Individual human energy. Individual-level energy and related constructs, such as relational energy (Owens et al., 2016), have attracted substantial attention in research. 
Research focusses on energy as energetic activation (Quinn et al., 2012). Energetic activation refers to the degree to which individual people, managers, and employees likewise feel energized. The construct is also discussed as energetic arousal (Thayer, 1989) or emotional energy (Collins, 1981; Quinn \& Dutton, 2005). These researchers consider energy mainly as an experience of positive affect, "a type of positive affective arousal, which people can experience as emotion — short responses to specific events — or mood-longer-lasting affective states that need not be a response to a specific event" (Quinn \& Dutton, 2005, p. 36).

Employees or managers who experience positive energy can present as a positive learning episode for their leadership capacity based on research that emphasizes generative effects of positive experience at work that can create endogenous change and resourcefulness in resources over time (Quinn et al., 2012). According to broaden-and-build theory (Fredrickson, 1998), energetic activation exhibited as positive emotion can result in generating new resources by expanding the breadth of a manager's and employee's $t$ and a repertoire, thus expanding leadership capability.

\section{Leadership}

Organizations face and create complex, evolving, or disruptive worlds, new forms of work and technologies, or growing/changing demands from employees. Leadership theory therefore shifted beyond leader-centric notions (Uhl-Bien, Riggio, Lowe, \& Carsten, 2014) and towards more inclusive and pluralistic conceptualizations of the leadership phenomenon. Leadership is a relational process (Bradbury \& Lichtenstein, 2000; Shamir, 2007), which consists of a series of reciprocal interactions among people (Denis, et al., 2012). It is a cocreated or socially co-constructed and emergent process (DeRue \& Ashford, 2010; Koonce, 2016), thus, both managers and employees collectively play an active part in leadership in formal and informal ways. 
Leadership therefore is a multi-level phenomenon (Batistič, Černe, \& Vogel, 2016; Dionne, Gupta, Sotak, Shirreffs, Serban, Hao, \& Yammarino, 2014). It manifests in individual and also collective forms, such as shared leadership and distributed leadership (Denis et al., 2012) in which leadership becomes a shared property of a unit (Day \& Harrison, 2007). Leadership then involves people at various levels in an organization and spreads across organizational boundaries over time. Consequently, such an understanding of leadership implies an expansive conceptualization of leadership development that includes building capacity of individuals as much as collectives to engage in leadership.

\section{Leadership Development}

Leadership development is of key interest because it focusses on developing humans a key ingredient of organizational success. Similar to the notion of leadership, leadership development is a dynamic and cyclical process (Van Velsor et al., 2004) of building leadership capacity at multiple organizational levels. For this chapter, which looks at individual and collective human energy, I focus on Day's (2000) distinction between leader development, which consists of creating leadership capacity in individual managers or employees, and developing collective capacity in teams, units, or events (DeRue \& Myers, 2014). Individual leader development processes involve skill, efficacy, and leader identity, as well as meaning-making in teams, whereas collective leadership development captures shared psychological safety, shared identities, and collective leadership skills and activities (Day, 2000; Day, Fleenor, Atwater, Sturm, \& McKee, 2014).

As a conceptual basis for the developmental processes, this chapter builds on experiential learning (e.g., Hoover, Giambatista, Sorenson, \& Bommer, 2010; Kolb, 1984) on the job. When individuals or teams face new, organizationally meaningful experiences that ask for shaping change with others (DeRue \& Myers, 2014), this stimulates them to expand or amend (DeRue \& Wellman, 2009; McCall, 2004; 2010) their individual or collective 
leadership capabilities. Experience-based learning builds on work assignments that stretch the capacity of managers, employees, or collectives (Reichard, Serrano, Condren, Wilder, Dollwet, \& Wang, 2015) and pushes them out of their comfort zones (McCall, 2004, 2010). However, research predominantly investigates learning from difficult and stressful events with adverse conditions that ask participants and collectives to deal with failure or setbacks (DeRue \& Wellman, 2009; Moxley \& Pulley, 2004).

Instead this chapter suggests learning from the episodes of strengths and positive experiences on the job, even if they are during difficult business situations. Episodes of positive human energy in this regard positively challenge employees and collectives out of their comfort zone (Bruch \& Vogel, 2011). These positive valence experiences (DeRue \& Workman, 2011) or "positive jolts" (Spreitzer, 2006) on the job in collective interactions build on a wide set of strengths and can stimulate learning and development to generate and leverage individual and specifically collective leadership capabilities. The following sections unpack the underlying processes and mechanisms that explain how positive human energy can stimulate the growth of leadership capacity in collectives, managers, and individual employees.

\section{Linking Positive Energy and Leadership Capacity}

This section relates, at multiple levels, the positive valence experiences of collective human energy and individual human energy (at both the manager and employee level) to the growth of leadership capacities in collectives and individuals (manager and employee) and thus reflects leadership as a relational, socially co-constructed process. In the following subsections, five avenues are proposed for how strengths-based positive experiences on the job can relate to creating and expanding leadership capacity (see Figure 1). 


\section{Linking Positive Collective Human Energy with Collective and Shared Leadership Capacity}

The relationship between human energy and the growth of collective and shared leadership capacity draws on the functioning of energy as a resource that allows actors to enact a new schema (Feldman \& Worline, 2011, p. 630), "where a schema is a cognitive framework that people use to organize their understanding of a situation" (Quinn et al., 2012, p. 9). The shared experience of enthusiasm, cognitive activation, and effort for joined goals can create a collective sense of mutuality or psychological safety (Edmondson, 1999) in team or unit members who, in turn, will get more involved in leadership interactions such as setting direction and motivating around distinct aspect of a team's work. Human energy then results in the growth of collective leadership capacity in that leadership can be enacted as a process to which many in the collective contribute to creating meaning, direction setting, deciding, motivating, or developing. As such, unit members enact in series of alternating individual and shared capacities, claiming and granting leadership independently of the role of an individual in the collective (DeRue \& Ashford, 2010), which sees the leadership role more shared among the unit members. In this regard, collective patterns of energy can generate change (Howard-Grenville, Golden-Biddle, Irwin, \& Mao, 2011), as leadership enactment and leadership capacity emerge as a shared property of a social system such as a team or unit (Day \& Harrison, 2007). 
For an explanation of the generative interaction among the collective, research also draws on Collins' (1981) interaction ritual chain (IRC) theory. IRC suggests that repeated, ritualistic interactions between interdependent organizational members over time create the energy for new social structures and processes (Quinn et al., 2012). These can manifest, for instance, in forms of plural leadership identified by Denis et al. (2012), such as sharing leadership for team effectiveness or producing leadership through interaction.

Proposition 1: Positive collective human energy as positive valence experience is supportive of building collective and shared leadership

\section{Linking Positive Collective Human Energy with Individual Managers' Leadership Capacity}

When managers are experiencing collective human energy, this experience can support creating and expanding individual and social leadership capacity in them. In research on leadership and positive phenomena, managers are often conceptualized as the independent factor (for exceptions, see Dvir \& Shamir, 2003; Graça \& Passos, 2012) that elicits leadership and beneficial consequences for organizations, teams, or individuals (Dvir \& Shamir, 2003). However, the contribution of followers to the leadership process is in line with our conceptualization of leadership as a relational co-created process (Fairhurst \& Uhl-Bien, 2012). While this research investigates the process of leadership, this chapter pursues a leadership development perspective.

Managers can interpret high levels of positive energy in teams or larger collectives, such as departments or units, as an indicator of accessible external strength, e.g., as access to information, expertise, and social and relational resources (Spreitzer, 1996). Likewise, when leaders perceive high levels of enthusiasm, cognitive alertness, and effort to work towards the team goals in their followers, this may work as a feedback mechanism about success from earlier leadership activities and thus provide implicit approval for a leader's current or future 
course of action. In turn, this may lift a manager's sense of empowerment, but also self-worth and personal growth as part of their self-concept (Howell \& Shamir, 2005), strengthen the manager's leader identity (DeRue \& Ashford, 2010), and expand their leadership efficacy (Hannah, Avolio, Luthans, \& Harms, 2008) as proximal development indicators of individual leadership capacity (Day \& Dragoni, 2015).

Furthermore, when managers experience that their employees jointly demonstrate high levels of enthusiasm, cognitive alertness, and effort for the shared purpose, this may create both an increased level of manager psychological safety (Day \& Dragoni, 2015; Edmondson, 1999) and identification towards the team, which, in turn, can raise aspects of collective identity (Brewer \& Gardner, 1996), such as the importance of collaboration, shared purposes, and communal motives in the definitions of a manager's self. Consequently, managers may endorse various other members of a team to enact the leader role for a period such that they develop an impetus towards enacting collective and shared leadership capacity.

Proposition 2: Positive collective human energy as a positive valence experience is supportive of expanding individual managers' leadership capacity

\section{Linking Positive Collective Human Energy with Individual Employees' Capacity for Leading}

For the individual employee, being part of high positive energy teams can facilitate them engaging in collective leadership processes. Experiencing attributes of collective human energy, such as a team's heightened alertness for business development, challenging the status quo to pursue shared aims and purposes (Cole, et al. 2012), might elevate an individual team member's sense of responsibility, purpose, and efficacy. This, in turn, can encourage an employee to engage in leadership interactions and processes, take the lead around distinct aspects of the task, and at times claim an informal, leadership role. Experiencing higher levels of collective enthusiasm might also expand the thought and action repertoire 
(Fredrickson \& Branigan, 2005) of people, which can result in adopting and experimenting with leadership claims, skills, and behavior.

A second line of thought builds on identity theory in leadership research (e.g., Lord, Gatti, \& Chiu, 2016; Lord \& Hall, 2005). Identity, or the self-concept, refers to how people define themselves or what people believe about themselves (Van Knippenberg, Van Knippenberg, De Cremer, \& Hogg, 2004). Predominantly in managers, it differentiates identity into individual, relational, and collective levels (Brewer \& Gardner, 1996; Day \& Harrison, 2007). A sustained positive valence experience of collective human energy, however, can also unlock experimenting and amending (Ibarra 1999; Ibarra, Wittman, Petriglieri \& Day, 2014; Lord et al., 2016) elements of the self-definition in employees over time and shifts an employee's identity construction towards the importance of relational and collective levels. First, people with strong relational facets of their identity place importance on close interpersonal relationships and their interpersonal influence (Brewer \& Gardner, 1996). Positive collective human energy can manifest as an experience of a network of mutually reinforcing positive relationships (DeRue \& Workman, 2014) and thus might expand the importance of engaging in and creating close relationships with others. The latter is a key ingredient for leadership and its development (Day \& Harrison, 2007). Second, people with strong collective identities (Brewer \& Gardner, 1996) define themselves regarding communal motives, associations with collectives, and regarding joint activities. The experience of the emergent property of collective energy and the positive shared purpose might make the collective perspective more relevant to employees and, as such, support the growth of collective-level facets of their selves. The developmental stimulus, in turn, can expand their capacity to engage in collective or shared types of leadership.

Proposition 3: Positive collective human energy as a positive valence experience is supportive of expanding individual employees' leadership capacity 


\section{Linking Positive Individual Human Energy with Individual Managers' Leadership Capacity}

While the focus so far has been on the developmental utility of positive collective human energy, the next two sections focus on organizational members' individual demonstration of energy. A manager's positive individual human energy can serve as a positive individual valence experience that is supportive of expanding their leadership capacity. Within episodes of collective human energy, a manager may also sense individual energetic activation depicted as the degree to which the person feels emotional energy and being energized (Quinn et al., 2012; Quinn \& Dutton, 2005). These episodes also present strengths-based positive valence experiences and, as such, a potential leadership learning episode that can strengthen or unlock further leadership capacity in managers. Energy as leader activation with high valence emotions (Quinn et al., 2012) can mobilize current resources and schema (Feldman, 2004) of leadership capability in new ways. That means when managers feel inherently vigorous they might engage more of their existing leadership skills and behavioral repertoire into experimenting with further leadership skills.

Furthermore, according to conservation of resources $(\mathrm{CoR})$ theory, individual human energy is a subjective experience of managers that they aim to retain, protect, and generate (Hobfoll, 1989). For managers who are experimenting with leadership skills, influence, and identity, this experience may be perceived as an opportunity to co-create the conditions where they can thrive and feel invigorated.

During unit or team processes, managers who experience a sense of personal vitality and energy as a developmental episode, in addition to their actual task focus, might strengthen their definition of self (i.e., their role identity) as a leader. This can be what DeRue and Workman (2011) call self-focussed experiences that make people aware of their potential and encourage them to strive for it. High-energy managers might therefore feel a sense of leader efficacy and psychological empowerment and self-determination (Howell \& Shamir, 
2005; Thomas \& Velthouse, 1990), which, in turn, can strengthen their own sense of identity as a leader as part of their definition of self and evoke a developmental impetus for increased and sustained enactment of collective, relational, and individual leadership capacity.

Proposition 4: Positive individual human energy as a positive valence experience is supportive of expanding individual managers' leadership capacity

\section{Linking Positive Individual Human Energy with Individual Employees' Capacity for Leading Upwards}

Individual employees who participate in high-energy teams, units, or other enabling factors may demonstrate positive individual energy such that the employee experiences energetic activation as personal feelings of vigor and emotional energy (Quinn et al., 2012). When employees individually experience energetic activation, this can be supportive of an organizational member's capacity to engage in leadership processes and specifically to build leading-up or followership behaviors. Due to the position that employees often adopt in hierarchical settings, it is worthwhile exploring how strengths-based, positive valence episodes create developmental impetus for enacting leading upwards or followership capacity (Uhl-Bien et al., 2014), which may expand the development impetus beyond traditional leadership skills and identity domain.

Followership focuses on "the nature and impact of followers and following in the leadership process" (Uhl-Bien et al., 2014, p. 84). Managers receive some form of influence from their employees, for instance, through their attributes, skills, and behaviors that specifically contribute to the leadership processes (Carsten, Uhl-Bien, West, Patera, \& McGregor, 2010; Graça \& Passos, 2012). Carsten et al. (2010) defined followership as schema or behaviors "of individuals acting in relation to a leader(s). In other words, followership behaviors are not about how individuals interact relative solely to their 
individual work (e.g., self-management, self-leadership) or other coworkers (e.g., shared leadership), but relative to those with higher status - with respect to leaders" (p. 545).

Subsequently, developing follower capacity from positive energy episodes ventures into followership development. Employees of high-energy units can experience a network of mutually reinforcing positive relationships which they, in turn, perceive as active participation and as such as a validation and reinforcement (DeRue \& Workman, 2011) of their own capacity and effort. This can elicit positive emotions of enthusiasm, vigor, or excitement (i.e., energetic activation) (Quinn et al., 2012) and provide a positive strengthbased valence experience that elicits additional cognitive and behavioral resources in an employee. However, it can also expand their sense of self with new elements relating to adopting an active follower identity in the co-creation of leadership processes.

According to broaden-and-build theory, positive emotional experiences create new resources, which show in an expanded momentary thought and action repertoire (Fredrickson, 1998; Fredrickson \& Branigan, 2005) such as experimenting or exploration, which, in essence, reflects elements of positive development cycles (DeRue \& Workman, 2011). This sense of individual strengths within the collective experience of energy and challenging the status quo and cognitive alertness may translate into employee feelings of influence towards the manager and thus expand into leading-up and followership activities. According to IRC theory (Collins, 1981), people seek activities to recreate situations of energy (Quinn et al, 2012) and, therefore, engage in processes and activities that recreate high-energy units. Building on an emerging proactive follower schema (Carsten et al., 2010), this can manifest in an employee without formal position challenging and supporting a manager in alignment, decision-making, or commitment, thus creating activities of expanded capacities.

In conjunction with the individual resources dynamic above, an overlapping process of identity expansion and experimentation with future identities can occur. The sense of strength 
and confidence from individually felt energetic activation and vigor within the environment of a high-energy and psychologically safe team (Edmondson, 1999) can function as an otherfocussed experience (DeRue \& Workman, 2011) that demonstrates how one's growth and development allows individual organizational members to positively affect others and may therefore stimulate development. The positive valence experience then shapes a developmental impulse where an employee might broaden the definition of self or choose to experiment with possible elements of a future or prospective self (Ibarra 1999) and selfexpansion by including the perspectives, behavior, and responsibilities of a manager into the self (Aron, Aron, Tudor, \& Nelson, 1991; Dansereau, Seitz, Chiu, Shaughnessy, \& Yammarino, 2013), which can manifest in an expanded repertoire of upwards influencing activities towards the manager.

Proposition 5: Positive individual human energy as a positive valence experience is supportive of expanding individual employees' capacity to enact leading-up

\section{Multi-level Conditions for Initial and Ongoing Positive Human Energy-Developing Leadership Capacity Linkages}

Scholarship on positive phenomena in organizations is intrigued and guided by researching generative mechanisms, processes, and structures with episodic, reinforcing, and cyclical thinking at its heart (Quinn et al., 2012 ); all of which expand rather than limit growth and learning capacity (Ragins \& Dutton, 2007). Identifying enabling conditions that promote initially or continuously the dynamics of the positive human energy-developing leadership capacity linkage is crucial. However, it is difficult to differentiate between initial conditions as antecedents, boundary conditions for the proposed relationships, or conditions shaping the expected outcomes of expanded leadership capacity. Also, improved or added collective and individual leadership capacity itself will influence the experience of positive collective and individual human energy in the future. The following section therefore 
discusses a set of multi-level enabling conditions that might initially and continuously propel the model dynamics of creating collective and individual leadership capacity from on-the-job positive valence experiences of positive jolts (Spreitzer, 2006). The section differentiates between factors at the person level, team level, and organizational level.

\section{Person-level Enablers}

Research on human energy suggests that building new resources in people is a key mechanism for transferring positive valence experiences of human energy into developmental impact for managers and employees. For within people enablers, an individual's initial resource-seeking motivation and behavior (Quinn et al., 2012) and how they then sustain this becomes salient to creating new resources. Dutton, Roberts, and Bednar (2010) suggest how different positive work-related identities help with accessing and building social resources and thus strengthen employees. Employees' and managers' sense making and reframing skills can help to identify on-the-job episodes as manifestations in high positive energy team processes and developmental opportunities for shaping leadership capacity.

Secondly, the literature points to attributes of individuals that may support processes of leadership development. Research, for instance, points to motivation to lead (Chan \& Drasgow, 2001), motivation to develop (Boyce, Zaccaro, \& Wisecarver, 2010), and the developmental readiness of leaders (e.g., Ely, Boyce, Nelson, Zaccaro, Hernez-Broome, \& Whyman, 2010), initial developmental level of followers (Dvir \& Shamir, 2003), or learning orientation (DeRue \& Myers, 2014). Also managers' humility (Owens \& Hekman, 2012) and their courage to step aside and create the space for their employees and managers (Bruch \& Vogel, 2011) might help others to develop capacity for leading.

Finally, research on identity points to factors that make individuals engage with identity work or identity construction (Ashforth \& Shinoff, 2015) and elicit ongoing changes in active identities and behavioral repertoires (Lord, et al., 2016). For instance, a manager's or 
employee's sense of meaningfulness (Baumeister, 1991), as the need to pursue purpose at work, or self-enhancement motives (Aron, et al., 1991), can elicit an inner debate about the definition of self and a receptiveness to challenge and/or re-construct elements of their identity as a manager or employee.

\section{Team-level Enablers}

This section focusses on distinct practices of team reflexivity (Graça \& Passos, 2012) and after-event feedback and debriefings (Konradt, Schippers, Garbers \& Steenfatt, 2015), and the shared process of positive organizing (Weick, 2003) as team-level enablers that provide a fruitful environment for the positive valence experience of human energydeveloping leadership capacity linkage.

Reflective team practices. To help develop collective leadership capacity from collective positive jolts (Spreitzer, 2006), teams and units can benefit from shared reflective practices that incorporate episodes of reflexivity or after-event feedback and debriefing (Konradt et al., 2015). After one or more high positive energy experiences, teams might establish shared states of team reflexivity, where teams reflect upon and modify objectives, strategies, and processes, for example. Team reflexivity has been suggested as a means of helping groups to reach a greater shared understanding of task strategies and goals (van Ginkel, Tindale, \& van Knippenberg, 2009). Moreover, the team clarifies the objective use of information needed to interpret the ambiguity in the environment, reduce uncertainty, and sense it as able to adapt to dynamic environments (Graça \& Passos, 2012). Reflexive practices then can support the ongoing noticing and interpretation of unfolding events and explore their potential implications, which can help to uncover perceptions of collective resourcefulness, individual and collective strengths in contributing and influencing, and, in turn, provide the experience and impulse to build and maintain collective and individual leadership capability. 
In addition, to cope with learning and complex environments, individual team managers and organizational members might experience role strain and difficulty in fulfilling role obligations (Goode, 1960). Thus, leaders performing different roles elicit team cognitive resources. Team members engaging in proactive leadership-type behavior (Carsten et al., 2010) at different times have more opportunity to respond to team members' learning and affective demands. Team reflexivity can then work as a catalyst for individual managers and employees to unpack this type of other-focused experience (DeRue \& Workman, 2011). These can manifest managers' and employees' positive and resourceful impact on others and, as such, reinforce and instill in them further learning and development of individual and shared leading.

Organizations can also encourage teams to embed practices of team feedback or afterevent team debriefings (Konradt et al., 2015) into their team event cycles to routinize team reflexivity. Research by Eddy, Tannenbaum, and Mathieu (2013) indicates that a team-led guided debrief intervention improved team processes. These can become psychologically safe spaces (Edmondson, 1999) in which team members more likely engage in experiential learning behaviors by removing barriers of fear, uncertainty, and self-defensiveness (Sanner \& Bunderson, 2015). Utilizing positively stimulating learning and development techniques, such as appreciate inquiry (Cooperrider \& Whitney, 2005), as a team-based diagnostic process can be a demonstration of positive collective human energy. As a generative learning process, it can uncover episodes of individual and shared accomplishment and elicit areas of further leadership skill or identity development. If teams expand their reflective activities on positive experiences and leadership events and processes in the team, this may evolve and, over time, sustain new capacities of individual and shared leadership behavior and identities in teams.

Positive organizing. Core research on positive organizing focuses predominantly on contexts that are high risk and demand high reliability (Weick \& Roberts, 1993). However, 
positive organizing and its attributes may also show potency for episodes and processes with increased task interdependence and limited predictability and prescriptiveness of activities, which characterizes the high positive energy demonstration of teams as much as some of the supportive team-level and organization-level processes and practices that leverage the generative relationship between positive valence experience of human energy and building leadership capacity.

- Respectful interactions, characterized by trusting others, being a trusting observer to others, the willingness to maintain self-respect, (Weick, 2003) and being seen as valued (Carmeli, Dutton, \& Hardin, 2015), can help shape fruitful interactions among team or unit members in situations of mutual challenge, such as collective positive energy episodes or shared feedback and reflexive practice about shared and individual leadership enactment and development potential.

- Heedful interrelating and its three main facets (Weick, 2003; Weick \& Roberts, 1993) can be an enabler to creating collective human energy and developing collective leadership capacity. Teams showing heedful interrelating demonstrate the shared properties of contributing to a wider system or towards each team member; subordinating, as fitting their own actions into the demands, needs, and flow of the team and participants; and representing, as envisioning and visualizing collective work and processes; yet, in this context, also envisioning co-created shared leadership capacity being realized by the team.

- Practices of reflexivity and mutual feedback may benefit from mindful organizing because it can help to navigate possible tensions between participants arising during and from feedback and reflexivity. Mindful organizing as a collective capability (Vogus, 2011) is constituted (Weick, 2003), for instance, by investigating organizational issues as an opportunity for supporting prosperity of organizations. It also shows when organizations invest time for observing interactions and outcomes, and they expect more 
complex functioning of the team. Finally, mindful organizing emphasizes finding and building local expertise in leadership that allows for collective and leadership capacity cocreated by many organizational members. Positive organizing and the impact on positive growth of capability can then specifically sustain the leadership capacity by making it reliable and resilient.

\section{Organization-level Enablers}

Research, such as on high-energy organizations (Bruch \& Vogel, 2011), positive leadership (Cameron, 2008), and positive organizations (Quinn, 2015), shows how organizational-level factors over time can support high-energy, positive, and capacitydeveloping organizations. Positive work environments can help the positive valence experience of the human energy-developing leadership capacity linkage to emerge and expand. The following outlines four highly interdependent areas of work environments or management systems (Bruch \& Vogel, 2011) and some specific factors that organizations can influence and/or see emerging.

Organizational purpose as meaning eliciting. Positive organizational environments are characterized by profound and shared purposes (Bruch \& Vogel, 2011; Cameron, 2008). This can provide shared positive meaning to organizational members across an organization because research sees an increased aspiration that work overlaps with a sense of meaning in life (Wrzesniewski, Dutton, \& Debebe, 2003) and supports the demand to be part of something larger and more significant than themselves (DeRue \& Workman, 2011). Organizations with purpose-rich contexts might support the emergence and sustained demonstration of excited, cognitively activated, and effortful high-energy teams. Those context can also provide a developmental stimulus to expand organization's capacity to lead individually and collectively towards the path to reaching the collective purpose. 
Culture and values. Values and culture are elements of positive work environments (Haertel \& Ashkanasy, 2010) and key management systems that strategic leaders can engage with for their organization (Cameron, 2008). To define culture, research points to the basic assumptions, values, and beliefs that are shared by members of an organization (Schein, 2009) and determine how organizations conduct their business, shape how people unconsciously operate, and view themselves and their organization.

It is key for energy-sustaining cultures (Bruch \& Vogel, 2011) to identify a set of generative shared values that involves, first, the content space of the culture (Cameron, 2008; Quinn, 2015), i.e., the specific beliefs and values that can help the organization to thrive, and, second, the actual strength of the value enactment or how deeply the values are embedded in an organization. With regard to stimulating the shared experience of human energy and the build-up of leadership capacity, an organization that creates a shared understanding regarding the importance of individual and shared learning, the significance and the type of leadership appreciated, and the meaning of collectiveness for success may be more likely to trigger or continue to generate energy as much as identity work and learning in organizational members.

Structure and relating. For positive work contexts that enable development of leadership capacity that is relational and co-created by a number of people, research points to providing flexible and fluid structures and processes. Such structures allow and encourage informal relationships for growth and change and add to more rigid configurations that allow for transparency and reliability.

Furthermore, the proposed nature of leadership and positive collective human energy highlights the significance of relationships among organizational members including managers and employees. Scholars focus on relationships that allow for meaningful interpersonal interactions (Wrzesniewski et al, 2003). Establishing and nurturing high-quality relationships becomes a key task for context setting. DeRue and Workman (2011) suggest 
that when organizations shape networks of mutually reinforcing positive relationships between people, these can transport purpose and meaning. They can also provide a further option of a psychologically safe environment for experimenting with new forms of the self and learning, and therefore help to define leadership identities and link those to larger purposes which, in turn, will encourage organizational members to expand their shared or individual leadership capacity.

Additionally, research focuses conceptually and empirically (e.g., Cross et al., 2003) on multi-dyadic or network-based relationships and how those help to create energy in collectives. When organizational members can construct and maintain high-quality connections with others (Dutton, 2003), i.e., reciprocal relationships with positive affect, regard and respect for others, resilience, and openness, this might have a dual effect on eliciting and maintaining energy-based positive valence learning experiences and, as shown above, leverage the mechanism that supports ongoing capacity development.

Leadership as a system of positive work environments. Leadership can support high energy-high leadership learning organizations in various ways. Often the focus is on individual manager's leadership capacity and how they create energy in their immediate employee relationships. Furthermore, leadership can be considered at the organizational level of analysis, for instance as positive strategic leadership (Cameron, 2008), or from a multilevel perspective. Then leadership can be considered as a management system that manifests as high-quality leadership in an entire organization across all levels (Bruch \& Vogel, 2011; Menges, Walter, Vogel, \& Bruch, 2011). This consideration can help many organizational members to flourish and demonstrate high energy on the job and, in turn, individual or shared growth and learning of leadership.

An organization can adopt various activities that facilitate a management system of organization-wide high-quality leadership. Embedding a shared and meaningful purpose across the organization, as developed above, is in itself a feature of high-quality leadership. 
Further an organization can encourage, endorse, and publicly acknowledge plural leadership (Denis et al., 2012) across the organization. Finally, for leadership as a system of positive work environments, an organization may want to explore a climate and embedded appreciation for developing leadership capacity across the entire organization. Positive, on the job experiences are a developmental opportunity for organizational members individually and collectively as a complementary process to programmatic capacity building that can affect many and not be necessarily restricted to a few employees. A climate for developing leadership capacity provides then a context and impulse to translate high-energy on-the-job episodes into individual or shared reflection on and building of leadership capacity.

\section{Future Research Directions}

\section{Maintaining Leadership Capacity Development as a Sustaining Energetic Experience}

This chapter looked at understanding the mechanisms and conditions that help to utilize high positive energy on-the-job experiences as nurturing leadership learning events. Research could further explore how expanded leadership capability in cyclical episodes over time shapes how individuals and teams demonstrate positive-energy episodes of high enthusiasm, alertness, and effort in pursuit of shared goals, and how the experience can be used to facilitate additional sustained learning. This section suggests two perspectives that need careful consideration when addressing sustained endogenous change in energy, resources, and capability and maintaining leadership capacity development.

First, if organizations manage to create repeated, ongoing positive human energydeveloping leadership capacity linkages, they may instill a positive climate for leadership development across the organization. While the leadership climate addresses the individual and collective quality of leadership across an organization, I define leadership development 
climate as the shared demonstration of emphasis, support, and engagement in building positive leadership capacity consistently throughout an organization.

Second, research can explore whether there is a tipping point when learning from positive valence experiences is saturated. Organizational members and teams may have accumulated through repeated cycles of reflexivity, debriefing, and personal reflecting and learning, an immense repertoire of leadership capacity in their knowledge base. However, research also shows that leadership knowledge may not automatically translate into employees enacting these insights and skills into leadership practice (Ahmadi, Vogel, \& Collins, 2016). Consequently balancing those two dynamics becomes an ongoing crucial task for positive leadership development as a building block for maintaining leadership capacity development.

\section{Beyond Context Simplicity in Developing Leadership Capacity from Positive}

\section{Experiences}

In a diverse, complex, interdependent, and digitalized reality, leadership learning is not context-free. Likewise, considering contextual influences may enhance the success of developmental interventions or learning on the job from experiences of collective and individual energy. However, understanding how leadership processes are affected by, and provide output to the contexts in which individuals, teams, and organizations operate has not been adequately considered in leadership (Osborn, Hunt, \& Jauch, 2002) and leadership development research (Avolio, Avey, \& Quisenberry, 2010). Several contextual variables have been shown as having impact on leadership (Osborn, et al., 2012; Porter \& McLaughlin, 2006). However, instead of focusing on individual factors (mono-factor context), it would be theoretically generative to considering more complex, multi-factor situational compositions (multi-factor contexts). These compositions would help to better depict current and future 
environments in which individuals, teams, and organizations engage in creating on-the-job leadership learning from high positive energy episodes.

Virtual contexts. Teams and units increasingly work as virtual, geographically dispersed teams in which members may not be physically present in the same location for some or all of the time (Gibson \& Gibbs, 2006). Collaboration becomes asynchronous among members in different time zones and shift patterns, often anchored in diversity of national cultures that endorse different behaviors of leadership. Furthermore, this type of work can often involve collaborators or contractors in network-type settings beyond organizational boundaries. These situations are not adverse or hardship situations, but more loose work environments. Leadership development research can explore how organizations in these multi-factor contexts can generate strings of positive valence experiences and support the translation into leadership capability and skills.

Digital contexts. Technology and digital technology become ever more intertwined in the activities, interactions, communication and collaboration between organizational members. Digital media enabled communication also seems to impact how individuals relate in various social settings (Butts, Becker, \& Boswell, 2015), but also blur the boundary between work and non-work (Reyt \& Wiesenfeld, 2015). Specifically, the use of social or Web 2.0 technologies within organizations may alter the nature of work and the relationships among organizational members (Cascio \& Montealegre, 2016), including managers and employees. Some argue that technologies enable more participative styles of leadership (Korzynski \& Pawel, 2013), while others put forward the view that these technologies limit face-to-face human interactions and, as such, non-verbal cues as sources for contagion and sharedness. This may well also be different for different types of generations in the workplace. These multi-factor digitized environments might favor leadership that has evolved from exclusively role-based authority into a shared property of a social system comprising by interdependencies of individuals, teams, and organizations (Cullen-Lester \& Yammarino, 
2016; Day \& Harrison, 2007). However, future research could explore how the positive human energy-developing leadership capacity linkages play out in such diverse, digitally facilitated contexts and how such environments can support or hinder conditions and mechanisms for building collective and individual leadership capacity from positive valence experiences. 


\section{References}

Ahmadi, A., Vogel B., \& Collins, C. (2016). An initial framework for the role of leader fear in the knowing-doing gap of leadership. In N. M. Ashkanasy, C. E. J. Härtel, W. J. Zerbe (Eds.), Research on emotion in organizations (Vol. 12, pp. 313-340). Bingley, England: Emerald. doi:10.1108/s1746-979120160000012011

Aron, A., Aron, E. N., Tudor, M., \& Nelson, G. (1991). Close relationships as including other in the self. Journal of Personality and Social Psychology, 60(2), 241-253. doi:10.1037/0022-3514.60.2.241

Ashforth, B. E., Schinoff, B. S., \& Rogers, K. M. (2015). "I identify with her," "I identify with him": Unpacking the dynamics of personal identification in organizations. Academy of Management Review, 41(1), 28-60. doi:10.5465/amr.2014.0033

Atwater, L., \& Carmeli, A. (2009). Leader-member exchange, feelings of energy, and involvement in creative work. The Leadership Quarterly, 20(3), 264-275. doi:10.1016/j.leaqua.2007.07.009

Avolio, B. Avey, J. B., \& Quisenberry, D. (2010). Estimating return on leadership development investment. The Leadership Quarterly, 21(4), 633-644. doi:10.1016/j.leaqua.2010.06.006

Barsade, S. G. (2002). The ripple effect: Emotional contagion and its influence on group behavior. Administrative Science Quarterly, 47(4), 644-675. doi:10.2307/3094912

Batistič, S., Černe, M., \& Vogel, B. (2016, accepted for publication). Just how multi-level is leadership research? A document co-citation analysis 1980-2013 on leadership constructs and outcomes. The Leadership Quarterly.

Baumeister, R. F., \& Vohs, K. D. (2002). The pursuit of meaningfulness in life. In C. R. Snyder, \& S. J. Lopez (Eds.), Handbook of positive psychology (pp. 608-618). New York, NY: Oxford University Press.

Boyce, L. A., Zaccaro, S. J., \& Wisecarver, M. Z. (2010). Propensity for self-development of leadership attributes: Understanding, predicting, and supporting performance of leader self-development. The Leadership Quarterly, 21(1), 159-178.

doi:10.1016/j.leaqua.2009.10.012 
Bradbury, H., \& Lichtenstein, B. M. B. (2000). Relationality in organizational research: Exploring the space between. Organization Science, 11(5), 551-564. doi:10.1287/orsc.11.5.551.15203

Brewer, M. B., \& Gardner, W. (1996). Who is this "we"? Levels of collective identity and self representations. Journal of Personality and Social Psychology, 71(1), 83-93. doi:10.1037/0022-3514.71.1.83

Bruch, H., \& Vogel, B. (2011). Fully charged: How great leaders boost their organization's energy and ignite high performance. Boston, MA: Harvard Business Review Press.

Butts, M. M., Becker, W. J., \& Boswell, W. R. (2015). Hot buttons and time sinks: The effects of electronic communication during nonwork time on emotions and work-nonwork conflict. Academy of Management Journal, 58(3), 763-788. doi:10.5465/amj.2014.0170

Cameron, K. S. (2008). Positive leadership. San Francisco, CA: Berrett-Koehler.

Cameron, K. S., Dutton, J. E., \& Quinn, R. E. (2003). Positive organizational scholarship: Foundations of a new discipline. San Francisco, CA: Berrett-Koehler.

Carmeli, A., Dutton, J. E., \& Hardin, A. E. (2015). Respect as an engine for new ideas: Linking respectful engagement, relational information processing and creativity among employees and teams. Human Relations, 68(6), 1021-1047. doi:10.1177/0018726714550256

Carsten, M. K., Uhl-Bien, M., West, B. J., Patera, J. L., \& McGregor, R. (2010). Exploring social constructions of followership: A qualitative study. The Leadership Quarterly, 21(3), 543-562. doi:10.1016/j.leaqua.2010.03.015

Cascio, W. F., \& Montealegre, R. (2016). How technology is changing work and organizations. Annual Review of Organizational Psychology and Organizational Behavior, 3(1), 349375. doi:10.1146/annurev-orgpsych-041015-062352

Chan, K.-Y., \& Drasgow, F. (2001). Toward a theory of individual differences and leadership: Understanding the motivation to lead. Journal of Applied Psychology, 86(3), 481-498. doi:10.1037/0021-9010.86.3.481 
Cole, M. S., Bruch, H., \& Vogel, B. (2011). Energy at work: A measurement validation and linkage to unit effectiveness. Journal of Organizational Behavior, 33(4), 445-467. doi:10.1002/job.759

Collins, R. (1981). On the microfoundations of macrosociology. American Journal of Sociology, 86(5), 984-1014. doi:10.1086/227351

Cooperrider, D. L., \& Whitney, D. (2005). Appreciative inquiry: A positive revolution in change. San Francisco, CA: Berrett-Koehler.

Cross, R., Baker, W., \& Parker, A. (2003). What creates energy in organizations? Sloan Management Review, 44, 51-56.

Cullen-Lester, K. L., Leroy, H., Gerbasi, A., \& Nishii, L. (2016). Energy’s role in the extraversion (dis)advantage: How energy ties and task conflict help clarify the relationship between extraversion and proactive performance. Journal of Organizational Behavior, 1003-1022. doi:10.1002/job.2087

Dansereau, F., Seitz, S. R., Chiu, C.-Y., Shaughnessy, B., \& Yammarino, F. J. (2013). What makes leadership, leadership? Using self-expansion theory to integrate traditional and contemporary approaches. The Leadership Quarterly, 24(6), 798-821. doi:10.1016/j.leaqua.2013.10.008

Day, D. V. (2000). Leadership development: A review in context. The Leadership Quarterly, 11(4), 581-613. doi:10.1016/s1048-9843(00)00061-8

Day, D. V., \& Dragoni, L. (2015). Leadership development: An outcome-oriented review based on time and levels of analyses. Annual Review of Organizational Psychology and Organizational Behavior, 2(1), 133-156. doi:10.1146/annurev-orgpsych-032414-111328

Day, D. V., Fleenor, J. W., Atwater, L. E., Sturm, R. E., \& McKee, R. A. (2014). Advances in leader and leadership development: A review of 25 years of research and theory. The Leadership Quarterly, 25(1), 63-82. doi:10.1016/j.leaqua.2013.11.004

Day, D. V., \& Harrison, M. M. (2007). A multilevel, identity-based approach to leadership development. Human Resource Management Review, 17(4), 360-373. doi:10.1016/j.hrmr.2007.08.007 
Denis, J-L, Langley, A., \& Sergi, V (2012) Leadership in the plural. The Academy of Management Annals, 6(1), 211-283. doi: 10.1080/19416520.2012.667612

DeRue, D. S., \& Ashford, S. J. (2010). Who will lead and who will follow? A social process of leadership identity construction in organizations. Academy of Management Review, 35(4), 627-647. doi:10.5465/amr.2010.53503267

DeRue, D. S., \& Myers, C. G. (2014). Leadership development: A review and agenda for future research. In D.V. Day (Ed.), The Oxford handbook of leadership and organizations (pp. 832-855). New York, NY: Oxford University Press. doi:10.1093/oxfordhb /9780199755615.013.040

DeRue, D. S., \& Wellman, N. (2009). Developing leaders via experience: The role of developmental challenge, learning orientation, and feedback availability. Journal of Applied Psychology, 94(4), 859-875. doi:10.1037/a0015317

DeRue, D. S., \& Workman, K. M. (2011). Toward a positive and dynamic theory of leadership development. In K. Cameron \& G. Spreitzer (Eds.), The Oxford handbook of positive organizational scholarship. New York, NY: Oxford University Press.

Dionne, S. D., Gupta, A., Sotak, K. L., Shirreffs, K. A., Serban, A., Hao, C., Yammarino, F. J. (2014). A 25-year perspective on levels of analysis in leadership research. The Leadership Quarterly, 25(1), 6-35. doi:10.1016/j.leaqua.2013.11.002

Dutton, J. E. (2003). Energize your workplace: How to create and sustain high-quality connections at work. San Francisco, CA: Jossey-Bass.

Dutton, J. E., \& Glynn M. A. (2008). Positive organizational scholarship. In: J. Barling \& C. L. Cooper (Eds.), The SAGE handbook of organizational behavior(Vol. 1: Micro Perspectives, pp. 693-712). Thousand Oaks, CA: Sage. doi:10.4135 19781849200448.n37

Dutton, J. E., Roberts, L. M., \& Bednar, J. (2010). Pathways for positive identity construction at work: Four types of positive identity and the building of social resources. Academy of Management Review, 35(2), 265-293. doi:10.5465/amr.2010.48463334 
Dvir, T., \& Shamir, B. (2003). Follower developmental characteristics as predicting transformational leadership: a longitudinal field study. The Leadership Quarterly, 14(3), 327-344. doi:10.1016/s1048-9843(03)00018-3

Edmondson, A. (1999). Psychological safety and learning behavior in work teams. Administrative Science Quarterly, 44(2), 350-383. doi:10.2307/2666999

Eddy, E. R., Tannenbaum, S. I., \& Mathieu, J. E. (2013). Helping teams to help themselves: Comparing two team-led debriefing methods. Personnel Psychology, 66(4), 975-1008. doi:10.1111/peps.12041

Ely, K., Boyce, L. A., Nelson, J. K., Zaccaro, S. J., Hernez-Broome, G., \& Whyman, W. (2010). Evaluating leadership coaching: A review and integrated framework. The Leadership Quarterly, 21(4), 585-599. doi:10.1016/j.leaqua.2010.06.003

Etzioni, A. (1968). The active society. New York, NY: Free Press.

Fairhurst, G. T., \& Uhl-Bien, M. (2012). Organizational discourse analysis (ODA): Examining leadership as a relational process. The Leadership Quarterly, 23(6), 1043-1062. doi:10.1016/j.leaqua.2012.10.005

Feldman, M. S. (2004). Resources in emerging structures and processes of change. Organization Science, 15(3), 295-309. doi:10.1287/orsc.1040.0073

Feldman, M. S., \& Worline, M. C. (2011). Resourcefulness: Resources, resourcing, and ampliative cycles in organizations. In K. S. Cameron \& G. M. Spreitzer (Eds.), Oxford handbook of positive organizational scholarship (pp. 629-641). Oxford, England: Oxford University Press. doi:10.1093/oxfordhb/9780199734610.013.0047

Fredrickson, B. L. (1998). What good are positive emotions? Review of General Psychology, 2(3), 300-319. doi:10.1037/1089-2680.2.3.300

Fredrickson, B. L., \& Branigan, C. (2005). Positive emotions broaden the scope of attention and thought-action repertoires. Cognition \& Emotion, 19(3), 313-332. doi:10.1080/02699930441000238

Gibson, C. B., \& Gibbs, J. L. (2006). Unpacking the concept of virtuality: The effects of geographic dispersion, electronic dependence, dynamic structure and national diversity on team innovation. Administrative Science Quarterly, 51, 451-95 
Goode, W. (1960). A theory of strain. American Sociological Review, 25, 483-496. doi:10.2307/2092933

Graça, A. M., \& Passos, A. M. (2012). The role of team leadership in Portuguese child protection teams. Leadership, 8(2), 125-143. doi:10.1177/1742715011434108

Haertel, C. E. J., \& Ashkanasy, N. M. (2010). Healthy human cultures as positive work environments. In N. M. Ashkanasy, P. M. Wilderom, \& M. F. Peterson, Handbook of organizational culture and climate (pp. 85-100). Thousand Oaks, CA: Sage. doi:10.4135/9781483307961.n6

Hannah, S. T., Avolio, B. J., Luthans, F., \& Harms, P. D. (2008). Leadership efficacy: Review and future directions. The Leadership Quarterly, 19(6), 669-692. doi:10.1016/j.leaqua.2008.09.007

Hobfoll, S. E. (1989). Conservation of resources: A new attempt at conceptualizing stress. American Psychologist, 44(3), 513-524. doi:10.1037/0003-066x.44.3.513

Hoover, J. D., Giambatista, R. C., Sorenson, R. L., \& Bommer, W. H. (2010). Assessing the effectiveness of whole person learning pedagogy in skill acquisition. Academy of Management Learning \& Education, 9(2), 192-203. doi:10.5465/amle.2010.51428543

Howard-Grenville, J., Golden-Biddle, K., Irwin, J., \& Mao, J. (2011). Liminality as cultural process for cultural change. Organization Science, 22(2), 522-539. doi:10.1287/orsc.1100.0554

Howell, J. M., \& Shamir, B. (2005). The role of followers in the charismatic leadership process: relationships and their consequences. Academy of Management Review, 30(1), 96-112. doi:10.5465/amr.2005.15281435

Ibarra, H. (1999). Provisional selves: Experimenting with image and identity in professional adaptation. Administrative Science Quarterly, 44(4), 764-791. doi:10.2307/2667055

Ibarra, H., Wittman, S., Petriglieri, G., \& Day, D. V. (2014). Leadership and identity: An examination of three theories and new research directions. In D. Day (Ed.), The Oxford 
handbook of leadership and organizations.

doi:10.1093/oxfordhb/9780199755615.013.015

Katz, D., \& Kahn, R. L. (1966). The social psychology of organizations. New York, NY: John Wiley.

Kolb, D. A. (1984). Experiential learning: Experience as the source of learning and development. Englewood Cliffs, NJ: Prentice-Hall.

Konradt, U., Schippers, M. C., Garbers, Y., \& Steenfatt, C. (2015). Effects of guided reflexivity and team feedback on team performance improvement: The role of team regulatory processes and cognitive emergent states. European Journal of Work and Organizational Psychology, 24(5), 777-795. doi:10.1080/1359432x.2015.1005608

Koonce, R. (2016). All in "the family": Leading and following through individual, relational, and collective mindsets. In R. Koonce, M. Bligh, M. K. Carsten, \& M. Hurwitz (Eds). Followership in action: Cases and commentaries (pp. 3-14). Bingley, England: Emerald.

Korzynski, P. (2013). Online social networks and leadership. International Journal of Manpower, 34(8), 975-994. doi:10.1108/ijm-07-2013-0173

Kozlowski, S. W. J., \& Klein, K. J. (2000). A multilevel approach to theory and research in organizations: Contextual, temporal, and emergent processes. In K. J. Klein, \& S. W. J. Kozlowski (Eds.), Multilevel theory, research and methods in organizations: Foundations, extensions, and new directions (pp. 3-90). San Francisco, CA: JosseyBass.

Lord, R. G., Gatti, P., \& Chui, S. L. M. (2016). Social-cognitive, relational, and identity-based approaches to leadership. Organizational Behavior and Human Decision Processes, 136, 119-134. doi:10.1016/j.obhdp.2016.03.001

Lord, R. G., \& Hall, R. J. (2005). Identity, deep structure and the development of leadership skill. The Leadership Quarterly, 16(4), 591-615. doi:10.1016/j.leaqua.2005.06.003 
Marks, M. A., Mathieu, J. E., \& Zaccaro, S. J. (2001). A temporally based framework and taxonomy of team processes. Academy of Management Review, 26(3), 356-376. doi:10.5465/amr.2001.4845785

McCall, M. W. (2004). Leadership development through experience. Academy of Management Executive, 18(3), 127-130. doi:10.5465/ame.2004.14776183

McCall, M. W. (2010). Recasting leadership development. Industrial and Organizational Psychology, 3(1), 3-19. doi:10.1111/j.1754-9434.2009.01189.x

Menges, J. I., Walter, F., Vogel, B., \& Bruch, H. (2011). Transformational leadership climate: Performance linkages, mechanisms, and boundary conditions at the organizational level. The Leadership Quarterly, 22(5), 893-909. doi:10.1016/j.leaqua.2011.07.010

Morgeson, F. P., \& Hofmann, D. A. (1999). The structure and function of collective constructs: implications for multilevel research and theory development. Academy of Management Review, 24(2), 249-265. doi:10.5465/amr.1999.1893935

Moxley, R. S., \& Pulley, M. L. (2004). Hardships. In C. McCauley \& E.V. Velsor (Eds.), The Center for Creative Leadership handbook of leadership development (2nd ed., pp. 183203). San Francisco, CA: Jossey-Bass.

Osborn, R. N., Hunt, J. G., \& Jauch, L. R. (2002). Toward a contextual theory of leadership. The Leadership Quarterly, 13(6), 797-837. doi:10.1016/s1048-9843(02)00154-6

Owens, B. P., Baker, W. E., Sumpter, D. M., \& Cameron, K. S. (2016). Relational energy at work: Implications for job engagement and job performance. Journal of Applied Psychology, 101(1), 35-49. doi:10.1037/ap10000032

Owens, B. P., \& Hekman, D. R. (2011). Modeling how to grow: An inductive examination of humble leader behaviors, contingencies, and outcomes. Academy of Management Journal, 55(4), 787-818. doi:10.5465/amj.2010.0441

Quinn, R. E., (2015). The positive organization: Breaking free from conventional cultures, constraints, and beliefs. Oakland, CA : Berrett-Koehler. 
Quinn, R. W., \& Dutton, J. E. (2005). Coordination as energy-in-conversation. Academy of Management Review, 30(1), 36-57. doi:10.5465/amr.2005.15281422

Quinn, R. W., Spreitzer, G. M., \& Lam, C. F. (2012). Building a sustainable model of human energy in organizations: Exploring the critical role of resources. The Academy of Management Annals, 6(1), 337-396. doi:10.1080/19416520.2012.676762

Porter, L. W., \& McLaughlin, G. B. (2006). Leadership and the organizational context: Like the weather? The Leadership Quarterly, 17(6), 559-576. doi:10.1016/j.leaqua.2006.10.002

Ragins, R. B., \& Dutton, J. E. (2007). Positive relationships at work: An introduction and invitation. In J. E. Dutton \& R. B. Ragins (Eds.), Exploring positive relationships at work (pp. 3-25). New York, NY: Lawrence Erlbaum Associates.

Raes, A. M., Bruch, H., \& De Jong, S. B. (2012). How top management team behavioural integration can impact employee work outcomes: Theory development and first empirical tests. Human Relations, 66(2), 167-192. doi:10.1177/0018726712454554

Reichard, R. J., Serrano, S. A., Condren, M., Wilder, N., Dollwet, M., \& Wang, W. (2014). Engagement in cultural trigger events in the development of cultural competence. Academy of Management Learning \& Education, 14(4), 461-481. doi:10.5465/amle.2013.0043

Reyt, J.-N., \& Wiesenfeld, B. M. (2015). Seeing the forest for the trees: Exploratory learning, mobile technology, and knowledge workers' role integration behaviors. Academy of Management Journal, 58(3), 739-762.doi: 10.5465/amj.2013.0991

Rost, J. C. (1991). Leadership for the twenty-first century. New York, NY: Praeger.

Ryan, R. M., \& Frederick, C. (1997). On energy, personality, and health: Subjective vitality as a dynamic reflection of well-being. Journal of Personality, 65(3), 529-565. doi:10.1111/j.1467-6494.1997.tb00326.x 
Sanner, B., \& Bunderson J. S. (2015). When feeling safe isn't enough: Contextualizing models of safety and learning in teams. Organizational Psychology Review, 5, 224-43. $10.1177 / 2041386614565145$

Schein, E. H. (2009). Corporate culture survival guide. San Francisco, CA: Wiley.

Shamir, B. (2007). Introduction: From passive recipients to active co-producers: Followers' roles in the leadership process. In B. Shamir, R. Pillai, M. C. Bligh, \& M. Uhl-Bien (eds), Follower-centered perspectives on leadership: A tribute to the memory of James $R$. Meindl (pp. 1-18). Charlotte, NC: Information Age Publishing.

Schippers, M. C., \& Hogenes, R. (2011). Energy management of people in organizations: A review and research agenda. Journal of Business and Psychology, 26(2), 193-203. doi:10.1007/s10869-011-9217-6

Spreitzer, G. M. (1996). Social structural characteristics of psychological empowerment. Academy of Management Journal, 39(2), 483-504. doi:10.2307/256789

Spreitzer, G. M., \& Sonenshein, S. (2004). Toward the construct definition of positive deviance. American Behavioral Scientist, 47(6), 828-847. doi:10.1177/0002764203260212

Thayer, R. E. (1989). The biopsychology of mood and arousal. New York, NY: Oxford University Press.

Tannenbaum, S. I. (1997). Enhancing continuous learning: Diagnostic findings from multiple companies. Human Resource Management, 36(4), 437-452.

Thomas, K. W., \& Velthouse, B. A. (1990). Cognitive elements of empowerment: An "interpretive" model of intrinsic task motivation. Academy of Management Review, 15(4), 666-681. doi:10.5465/amr.1990.4310926

Uhl-Bien, M., Riggio, R. E., Lowe, K. B., \& Carsten, M. K. (2014). Followership theory: A review and research agenda. The Leadership Quarterly, 25(1), 83-104. doi:10.1016/j.leaqua.2013.11.007 
Van Ginkel, W., Tindale, R. S., \& van Knippenberg, D. (2009). Team reflexivity, development of shared task representations, and the use of distributed information in group decision making. Group Dynamics: Theory, Research, and Practice, 13(4), 265-280. doi:10.1037/a0016045

Van Knippenberg, D., van Knippenberg, B., De Cremer, D., \& Hogg, M. A. (2004). Leadership, self, and identity: A review and research agenda. The Leadership Quarterly, 15(6), 825856. doi:10.1016/j.leaqua.2004.09.002

Vogel, B., \& Bruch, H. (2011). Organizational energy. In K. Cameron \& G. Spreitzer (Eds.), The Oxford handbook of positive organizational scholarship (pp. 691-702). New York, NY: Oxford University Press. doi:10.1093/oxfordhb/9780199734610.013.0052

Vogus, T. J. (2011). Mindful organizing: Establishing and extending the foundations of highly reliable performance. In K. Cameron \& G. Spreitzer (Eds.), The Oxford handbook of positive organizational scholarship (pp. 664-676). New York, NY: Oxford University Press. doi:10.1093/oxfordhb/9780199734610.013.0050

Weick, K. E. (2003). Positive organizing and organizational tragedy. In K. S. Cameron, J. E. Dutton, \& R. E. Quinn (Eds.), Positive organizational scholarship: Foundations of a new discipline (pp. 66-80). San Francisco, CA: Berrett-Koehler.

Weick, K. E., \& Roberts, K. H. (1993). Collective mind in organizations: Heedful interrelating on flight decks. Administrative Science Quarterly, 38(3), 357-381. doi:10.2307/2393372

Wrzesniewski, A., Dutton, J. E., \& Debebe, G. (2003). Interpersonal sensemaking and the meaning of work. Research in Organizational Behavior, 25, 93-135. doi:10.1016/s01913085(03)25003-6 
Figure 1: A framework for the positive human energy experience-developing leadership capacity linkage

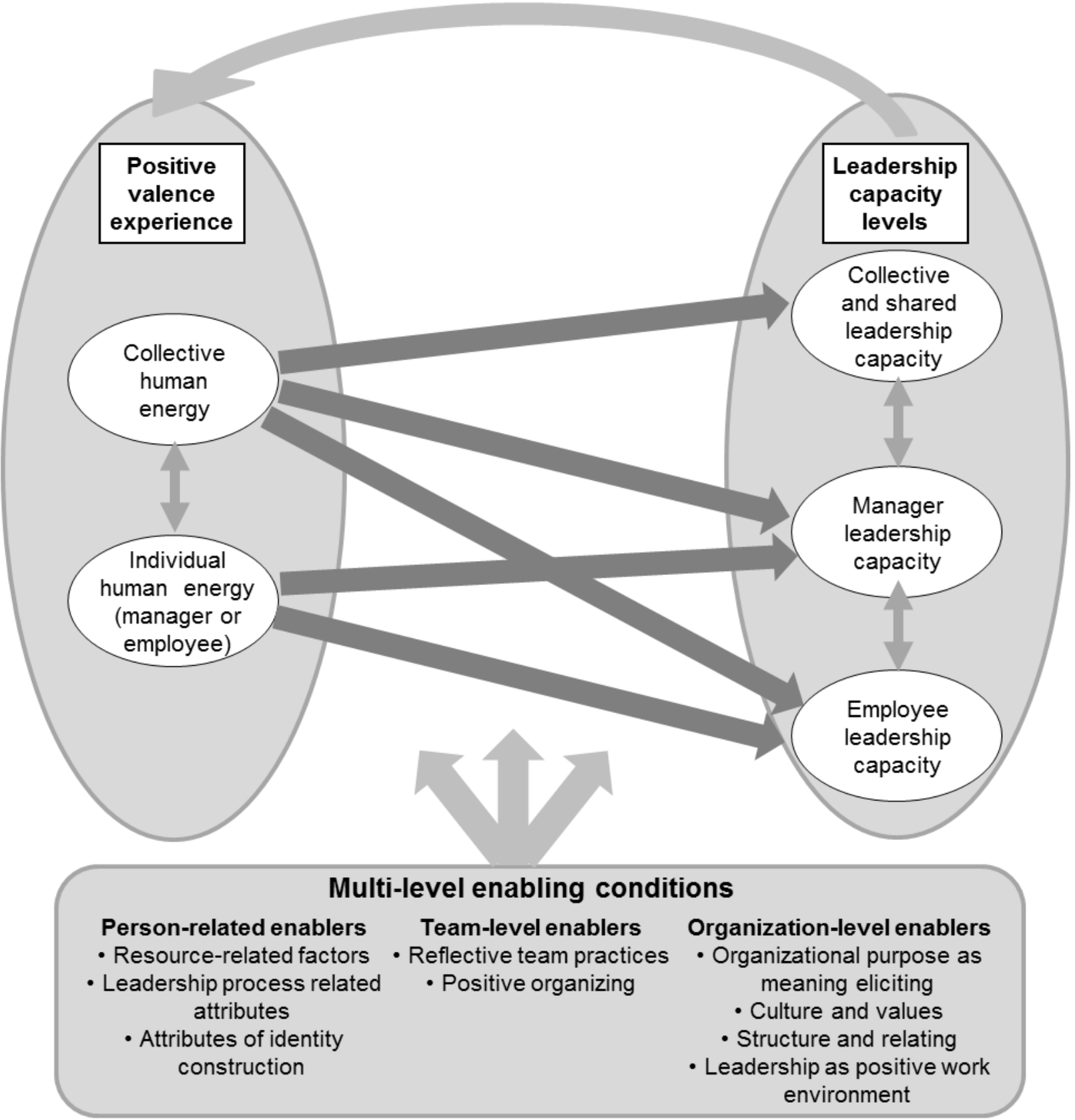

